\title{
La política desde el campo: iniciativas locales y gobierno rural en tiempos reformistas (Santa Fe, virreinato del Río de la Plata a finales del siglo XVIII)*
}

\author{
por \\ Darío G. Barriera ${ }^{1}$ \\ (ISHIR/CESOR - CEHISO/UNR - INHID)
}

Este artículo analiza iniciativas locales de un grupo de vecinos rurales en el Río de la Plata para ocuparse de un capitulo ausente en la Real Ordenanza de Intendentes de Buenos Aires (1782): el gobierno de las campañas. El texto plantea que la dicotomía «imposición o resistencias» a los procesos de centralización no agota la paleta de experiencias históricas. Documentando la existencia de una rica vida política en una campaña marginal del virreinato rioplatense durante el último cuarto del siglo XVIII, hace visible el modo en que los procesos territoriales "desde abajo» incidieron en la arquitectura institucional del período.

Palabras Clave: política; justicia; reformas borbónicas; gobierno rural; Río de la Plata.

Cómo citar este artículo / Citation: Barriera, Darío G., "La política desde el campo: iniciativas locales y gobierno rural en tiempos reformistas (Santa Fe, virreinato del Río de la Plata a finales del siglo XVIII)", Revista de Indias, LXXVII/270 (Madrid, 2017): 521-549, doi:10.3989/revindias.2017.017.

* Este trabajo se realizó en el marco del Proyecto de Investigación PIP 0023-2013-2015 GI "Justicias de Proximidad y organización del territorio. Normas, procedimientos y culturas jurídicas de jueces menores en Tucumán, Mendoza y Santa Fe (1782-1833)" financiado por CONICET (Rep. Argentina) y además fue discutido con los colegas que integran el ECOS-SUD A14-H02, "Orden público y organización del territorio: Francia, España, Cuba y el Río de la Plata, siglos XVIII-XIX”, Université de Toulouse Jean-Jaurés (Francia)/CONICET, Universidad Nacional de Rosario (Argentina)-2015/2017.

1 dgbarriera@conicet.gov.ar ORCID iD: http//orcid.org/0000-0003-3708-8301. 


\section{Planteo inTRODUCTORIO}

Uno de los grandes atractivos de la historia política colonial del siglo XVIII consiste en el desafío de pensar la diversidad y la riqueza de las situaciones que desataron localmente las reformas implementadas por la dinastía de Borbón para gobernar los territorios americanos de la monarquía hispánica. El tema no es nuevo -Horst Pietchsmann glosaba hace ya 20 años lo mucho que se había escrito sobre el impacto del reformismo en América desde los años 1950-, pero los enfoques variaron muchísimo desde entonces, pudiendo afirmarse que no solamente se enriqueció la querella de interpretaciones sino que se transformó completamente el modo de abordar el tema².

Las reformas comenzaron muy tempranamente y, desde finales del primer cuarto del siglo XVIII afectaron aspectos cruciales de la organización política del territorio que aquí se analiza ${ }^{3}$. Sin embargo, mi atención se enfoca ahora en un fragmento de las más tardías, referido al impacto territorial del reordenamiento administrativo impulsado por la Real Ordenanza para el establecimiento e instrucción de Intendentes de Ejército y Provincia en el Virreinato de Buenos Aires del 28 de enero de 1782.

Quienes por entonces fueron los flamantes intendentes del Río de la Plata impulsaron las políticas de gobierno contenidas en el mencionado instrumento encontrando diferentes grados de dificultad ${ }^{4}$ o resistencia a su aplicación, sobre todo en los niveles más bajos de la administración territorial, donde algunos de sus capítulos fracasaron ${ }^{5}$. No obstante, no son las «resistencias locales» al modelo las que despiertan mi interés sino, al contrario, la forma en que los agentes locales resolvieron políticamente asuntos imprevistos o

2 Pietchsmann, 1994; 1996. Se discuten desde entonces las interpretaciones de Guerra, 1988, y un excelente estado del debate a inicios de los años 1990 lo concentra la obra colectiva de Annino, Castro-Leiva y Guerra, 1994. Ejemplos de la renovación en los enfoques a los que refiero Castro, 1995. Serulnikov, 2006. Morelli, 2005, al cual me siento más próximo.

3 Tarragó, 2006. Birocco, 2011. Barriera y Fradkin, 2014.

${ }^{4}$ En su estudio sobre la "Causa de policía", glosando un testimonio de Sobremonte, Edberto Oscar Acevedo señaló la dificultad operativa que los intendentes encontraban para desarrollar sus políticas en la «dispersión» de la población. Acevedo, 1995: 63.

5 Por ejemplo a la suspensión de la capacidad de elegir alcaldes ordinarios cada año. Contra lo que mandaba la Real Ordenanza de Intendentes, el virrey Arredondo se la restituyó al cabildo santafesino en 1791. Archivo General de la Provincia de Santa Fe, Santa Fe (AGSF), Varios Documentos 1634-1816, leg. 20 (22 de enero de 1791), fol. 10. Véase también la copia del oficio del Virrey Nicolás de Arredondo, del 12 de enero, participando que, por orden del 15 de septiembre, el Rey había concedido al Cabildo de Santa Fe permiso para elegir anualmente los Alcaldes Ordinarios «no obstante lo prescripto en los artículos 8 y 116 de la Ordenanza de Intendente». 
alojados en zonas grises de la reglamentación monárquica. Estos aparecieron sobre todo a causa de que los cabildos dieciochescos del Río de la Plata, sedes de poder político de extensas jurisdicciones heredadas de las que los fundadores de ciudades habían asignado a finales del siglo XVI, enfrentaban dos siglos más tarde el desafío de gobernar poblaciones caracterizadas por ellos mismos como «muy crecidas y dispersas». Para encarar los problemas que proponía la circulación de personas y de cosas en esas jurisdicciones enormes y en pleno proceso de «espacialización» productiva-que implicaba fenómenos tales como el incremento de la delincuencia en los caminos y los campos- contaban con instrumentos jurídicos, políticos y judiciales que pertenecían al equipamiento político del siglo XVI y XVII: alcaldes provinciales, de la hermandad y cuadrilleros eventuales, pobremente armados, patentemente insuficientes para, tomando una expresión de la época, «asegurar la tierra».

En Santa Fe del Río de la Plata, este proceso -cuyo relato debe colocar en la larga duración las políticas concurrentes de la gobernación y el obispado desde los tiempos de Zabala (años 1730), considerar la erección de un tercer curato «rural» en Coronda (1749), y la acción sistemática del cabildo con el nombramiento de jueces de comisión para delitos específicos en los campos (desde 1766) - tiene por una de sus características principales el fuerte incremento de la designación de jueces de proximidad para las campañas, fenómeno que no está contemplado en la Real Ordenanza de 1782.

El caso no es único: bajo diferentes nombres y modalidades, los jueces rurales $^{6}$ se multiplicaron a lo largo y a lo ancho de todos los territorios alcanzados por la Real Ordenanza de Intendentes ${ }^{7}$, y esta diversidad refuerza el diagnóstico que proponía al inicio del trabajo, ya que responde a la ausencia de una planificación minuciosa sobre este tema que la Ordenanza dejó abierto: el modo concreto a través del cual los cabildos debían alcanzar localmente los objetivos de buen gobierno en los territorios sujetos a su jurisdicción -la administración de la justicia, la recaudación de las rentas, el mantenimiento de la pax publica, el reclutamiento de los hombres para la milicia y la guerra en las áreas rurales- no fue objeto del articulado. Quizás la más importante de las consecuencias de esta imprevisión fue el dejar pendiente la cuestión de las justicias rurales (inferiores o menores), porque en ese «humus» maduró la subdivisión política de los territorios existentes, que acabó por fraguar a caballo de las reformas y las guerras de independencia.

\footnotetext{
6 Sobre la justicia rural desde la historia del derecho, Storni, 1997. Un examen historiográfico en Barriera, 2013b.

7 Sobre la Real Ordenanza, Levaggi, 2008. Mariluz Urquijo, 1995.
} 
En este trabajo exploro la formulación de un tipo de construcción política imprevisto por la Real Ordenanza de Intendentes de 1782: a través de un enfoque microanalítico, muestro e interpreto el proceso que planteó la aparición de nuevas dimensiones territoriales en el interior de la jurisdicción santafesina, localizando el observatorio en la subdivisión de un territorio rural que se extiende inmediatamente al sur/suroeste de la ciudad de Santa Fe entre 1784 y 1789, cuando la superintendencia de Guerra y Hacienda de Buenos Aires estuvo a cargo del virrey del Río de la Plata $(1788)^{8}$. Utilizo información que proviene de las actas capitulares santafesinas, de algunos expedientes resultantes de la comunicación entre los pobladores, el cabildo, mediadores y el virrey-intendente y providencias enviadas por éste al cabildo.

\section{UNA POBLACIÓN EN MOVIMIENTO}

Santa Fe es la ciudad más antigua de la gobernación del Río de la Plata, pero siempre fue sufragánea: desde su fundación en 1573 dependió de la gobernación del Paraguay con sede en Asunción. Hasta 1593 su cabildo fue presidido por un teniente de adelantado-gobernador y desde entonces y hasta 1617, por un teniente de gobernador nombrado desde Asunción. Cuando en diciembre de ese año el Rey escindió la «provincia gigante» en dos, Santa $\mathrm{Fe}$ fue puesta bajo la jurisdicción de la nueva gobernación cuya cabecera se estableció en Buenos Aires. La creación del virreinato en 1776 y la erección de dos Audiencias en Buenos Aires (la primera entre 1661 y 1671 y la segunda desde 1785), no cambiaron su suerte. Tampoco fue sede principal en materia de organización eclesiástica. Estos datos me llevaron a conceptualizar su cultura política como «sufragánea», es decir, la de una ciudad que tramó todas sus relaciones con instituciones políticas y religiosas próximas (americanas) en materia secular (justicia, gobierno, hacienda, guerra) y eclesiástica, siempre desde el lugar de la dependencia. Nunca ocupó la máxima jerarquía en ninguna de las configuraciones institucionales, siempre tuvo muy cerca jerarquías inmediatamente superiores. El punto es importante porque exige de los agen-

8 El 23 de agosto de 1788 Francisco de Paula Sanz envió un pliego al cabildo santafesino notificando «...que en virtud de la copia de la Real Orden que incluie tiene agegada su Magestad la Superintendencia de Real Hazienda de todo este virreinato al mando del exmo. Sr. Virrey Marques de Loreto...», AGSF, Actas de Cabildo (en adelante AC), tomo XV B, fol. 302 . 
tes concretos aprendizajes y estrategias disímiles de las culturas centralistas o metropolitanas 9 .

Durante el siglo XVIII, la «población» de esta ciudad y de sus términos -planteados desde la fundación como una jurisdicción de 50 leguas a los cuatro vientos, pero que fue contrayéndose al roce con las de Córdoba y Santiago del Estero al oeste, Corrientes al nordeste y Buenos Aires al sur- se incrementó de manera sostenida y creciente. Si sobre el hecho secular no pueden echarse dudas, el problema de exponer qué significa «población santafesina» y qué fenómenos expresa el registro heurístico de dicho incremento sigue siendo relevante.

«Población santafesina» alude genéricamente al número de personas que estuvieron sujetas al cabildo santafesino. Su composición variable puede calcularse tomando en cuenta cifras de piso y techo (nadir y cénit secular a partir del cual se afirma incremento de la población) que se construyen con base en extrapolaciones realizadas a partir de indicadores «sugestivos» $-i$. $e$. un padrón de pobladores con estancia, algunas matrículas de pueblos de indios, comentarios de viajeros ${ }^{10}$. El siglo XVIII comienza con la presión que abipones y mocovíes ejercían sobre la ciudad: entradas indígenas sobre las estancias, sobre las chacras cercanas a la ciudad y sobre la ciudad misma ${ }^{11}$, agitaban los fantasmas de un segundo trasiego: los vecinos se plantearon la idea de volver a mudar la ciudad ${ }^{12}$. Los mocovíes ocupaban el oriente del Chaco central y habían comenzado su desplazamiento hacia el sur, jurisdicción norte de la ciudad de Santa Fe, movimiento que se consolidó con las entradas punitivas a cargo del gobernador del Tucumán Urízar y Arespacochaga desde $1710^{13}$.

En los años 1720, los vecinos de Santa Fe dudaban sobre sus posibilidades para sostener la ciudad pero no sobre su importancia estratégica. Además, y no obstante el oscuro panorama, los libros parroquiales santafesinos inauguran el registro de nacimientos en el pago del Salado y, de manera intermitente, de los de Coronda y Rincón. Para la década de 1730 existe consenso sobre que Santa Fe y sus campañas estaban habitadas por unas 7.000 personas del gru-

9 "La cultura sufragánea: lenguajes, saberes y conductas de la dependencia política y jurisdiccional", en evaluación.

10 Véase Viglione, 2003; 2005; 2008. García, 1997. Barriera, 2014.

11 Nesis, 2005: 14.

12 Manuel María Cervera, Historia de la Ciudad y Provincia de Santa Fe, Santa Fe, 1907: 574. Santa Fe se había trasladado de su primer sitio junto al río San Javier a este junto al Salado entre 1653 y 1660.

13 Sobre Urízar véase Tarragó, 2006: 101 y ss. Sobre la movilidad (voluntaria y forzada) de los abipones véase Nesis, 2005. 
po poblacional euro-criollo ${ }^{14}$, la mayoría dispersa en pequeñas unidades de producción rural ubicadas en los términos más cercanos -el Rincón, el Salado, los Cululú, para la época «expulsores» de familias por la situación en la frontera norte-, en Bajada (actual Paraná) u otros más alejados como Coronda (diez leguas al sur de la ciudad) y los Arroyos -región espacialmente considerada como una unidad de tránsito entre el borde sur del río Carcarañá y los arroyos de las tres hermanas al norte de la jurisdicción bonaerense- que entre 1720 y 1730 absorbieron gran parte de las migraciones forzadas que criollos e indígenas reducidos emprendieron presionados por indios libres.

Las divisiones y subdivisiones que las prácticas hereditarias infringieron a las mercedes de tierra otorgadas a finales del siglo XVII sobre el territorio de Coronda-Los Arroyos desde comienzos del XVIII, favorecieron la instalación de pequeños agrupamientos humanos alrededor de capillas de estancia, generando actividades pecuarias (primero) y agrícolas (más tarde), que lógicamente precedieron al establecimiento de cualquier tipo de autoridad secular o eclesiástica. Las medidas que tomó el gobernador Bruno Mauricio de Zabala para «asegurar las fronteras» ${ }^{15}$ sobre el final de su gobierno así como el desplazamiento de familias y pueblos de indios desde los pagos del norte hacia el sur, fortalecieron el poblamiento del eje Coronda-Capilla del Rosario. Durante la década de 1740 la ciudad transitaba un período de relativa estabilidad: las alianzas con líderes indígenas que «se comprometían a guardar la paz y a brindar ayuda militar frente a los grupos no reducidos» ${ }^{16}$ (de allí su designación como «indios amigos» a los cuales los «vecinos» se comprometían a abastecer con víveres y los jesuitas a gestionar su «vida en policía») se expresó en la fundación de la reducción de San Javier (1743 primera de mocovíes a la cura de los jesuitas en jurisdicción santafesina) y la de San Jeró-

14 Utilizo la expresión para simplificar la compleja composición de una población de origen europeo -reciente o antiguamente entrada al territorio, a sus descendientes y a quienes componen sus unidades domésticas- no en función de una identidad biológica sino de una identificación sociopolítica con la población que los propios agentes clasificarían como «española» o «criolla». Esta distinción es para facilitar la comprensión de informaciones vagas e imprecisas, típicas de las sociedades preestadísticas y no supone ningún tipo de homogeneidad interna de estos conjuntos. Su utilidad funcional se agota en este punto. Declino hablar de «grupo blanco» (expresión elegida por otros autores) por sus connotaciones raciales.

15 Griselda Tarragó (2012), indica que la situación de «inseguridad» comienza a mejorar desde 1734, con la designación de dos miembros notables del grupo mercantil (también de la elite capitular) santafesino: Francisco Javier de Echagüe y Andía como teniente de gobernador y la de Francisco de Vera Muxica. Tarragó señala que enfrentaron personalmente estos problemas por el deterioro que implicaban en sus propios negocios.

16 Nesis, 2005: 16. 
nimo (1748, de abipones, también bajo la égida jesuita $)^{17}$. En 1744 la ciudad registraba 205 vecinos y «63 soldados», lo que permite presumir unos 1.000 habitantes dentro del trazado urbano. Juan Álvarez estimó que, hacia el mismo momento, la zona al sur del Carcarañá, impulsada por el establecimiento reciente de explotaciones agrícolas de pequeñas dimensiones estaba poblada por unos 1.300 eurocriollos $^{18}$.

La población indígena es muy difícil de calcular con exactitud. Incluso si nos atenemos a la población reducida -aparte de las mencionadas se crearon o reinstalaron otras en $1750,1753,1760,1774,1780-19$ la variación de la población de las reducciones es permanente ${ }^{20}$. La tendencia centrífuga que signó el movimiento de la población de Santa Fe y sus chacras entre 1720 y 1730 se revirtió tras la asignación del privilegio de Puerto Preciso (1739), y sobre todo entre 1750 y 1790, cuando la ciudad y sus distritos más próximos recibieron una nutrida migración proveniente de «las ciudades de arriba» y sus campañas, donde la actividad ganadera y agrícola comenzaba a reproducirse más allá del autoconsumo ${ }^{21}$. A comienzos de 1760 , con motivo del envío de la Bula de la Santa Cruzada, se empadronó a los vecinos de los partidos del Salado y de Rincón, donde se registraron 90 y 47 familias respectivamente, lo cual representa una imagen muy diferente a la del abandono total de $1721^{22}$, área sobre la cual habría que confrontar con datos intermedios como propuse para Coronda entre 1724 y 1749.

Los nuevos pobladores, a veces temporales, ya que para muchos el territorio santafesino fue una escala hacia la campaña bonaerense ${ }^{23}$, venían casi siempre precedidos de la reputación de «perjudiciales», ya que se trataba sobre todo de familias e individuos sueltos desterrados de aquellas jurisdic-

17 Sobre la reducción de San Javier, Nesis, 2005. Sobre la de San Jerónimo, Lucaioli, 2005. Sobre el carácter jurisdiccional de ambas, Moriconi, 2012.

18 Carta a S. M. del Gobernador Ortiz de Rozas (1744), citada por Álvarez, 1992, cap. IV.

19 De mocovíes, abipones, mocoretás, calchines y colastinés. Algunas eran desplazamientos o fusiones de las ya existentes. Para un examen de las diferentes formas adoptadas y los agentes eclesiásticos y seculares involucrados, véase Moriconi, 2012.

20 Así lo demuestran Lucaioli, 2005 y Moriconi, 2012.

21 En mi análisis del Padrón de Benegas y Frías (1738), sugiero que el abandono de la zona que se extiende entre la laguna de Coronda y el río Carcarañá nunca fue completo y que entre 1724 y 1749 debe considerarse un constante movimiento de poblaciones (eurocriollas e indígena) discutiendo el territorio. Cfr. Barriera, 2014.

22 Gracias a este empadronamiento se confirma que el partido del Salado corre hasta el paso de Santo Tomé y que desde allí comienza el pago de San Jerónimo o Coronda, AGSF, AC, tomo XIII, 17 de marzo de 1760.

23 Canedo, 993: 7-29. Garavaglia, 2009. 
ciones $^{24}$. La epidemia de viruela de 1778, que causó estragos en Pergamino, Arrecifes, Arroyo de Tala, Rincón de San Pedro, Baradero y San Nicolás, no parece haber afectado particularmente a los poblados santafesinos ${ }^{25}$.

Según el informe del procurador Larramendi, la ciudad de Santa Fe tenía en 1795 entre 4.000 y 5.000 habitantes eurocriollos; no difiere mucho su apreciación de la que legó Félix de Azara (1797) quien además aventuró la cifra de 12.600 habitantes $^{26}$. Para Rincón la cifra era de 700 eurocriollos y Cervera afirma que en 1799 el fuerte de Sunchales, montado en 1790, agrupaba 1.113 habitantes en total ${ }^{27}$. Rosario era un pueblo que tenía por entonces unas 80 casas y ranchos alrededor de su parroquia, y en los alrededores -según Pedro Tuella, quien publicó estos datos en el Telégrafo mercantil, 1802- más de 84 estancias productivas, pudiendo ponderarse el número de pobladores en 5.879 , entre los cuales distinguió en el recuento 265 esclavos (pardos y morenos, de ambos sexos) así como a 274 pardos libres contra solo 9 morenos, también libertos ${ }^{28}$.

El incremento de la «población santafesina» del siglo XVIII, entonces, se apoya en el crecimiento y expansión de las familias asentadas en la ciudad nueva, las chacras y los campos desde la segunda mitad del siglo XVII pero también y sobre todo en una historia de movilizaciones: de esas mismas poblaciones, de las migraciones de los pueblos de arriba, de las migraciones provocadas por la presión exitosa de mocovíes y abipones sobre el norte y noroeste de la ciudad, de la organización de la población indígena en pueblos pero también del refinamiento de tecnologías de gobierno: la consolidación de ciertas parroquias como curatos (Rosario y Paraná en 1730, Coronda en 1749), la realización de algunos padrones (como el de 1738) y la mayor presencia de los alcaldes, comisionados y pedáneos en sus pagos, favorecieron una mayor concurrencia y comunicación entre las autoridades seculares y eclesiásticas con esas poblaciones dispersas, lo cual permitió registros en áreas hasta entonces no relevadas. Algo similar sucede con el notable incremento de registros posterior a 1787, deudor de la extensión del área cubierta por los curas párrocos y sus tenientes.

24 Suárez y Tornay, 2003: 534. Esto también aparece señalado en trabajos sobre Santiago del Estero o Río Cuarto. Farberman, 1997. Rustán, 2005. Barral, Fradkin y Perri, 2007.

25 Viglione, 2008: 92-109.

${ }^{26}$ Sin incluir indios reducidos y sueltos, de los cuales sabemos que existían 3.500 en los Arroyos y 2.000 en Coronda, para toda la jurisdicción. Informe del Procurador José Teodoro de Larramendi (1795), Cervera, 1980, tomo III, Apéndice, XXVII.

27 Cervera, 1980, tomo I: 562.

28 Tuella, 1865. 
Una de las razones invocadas al respecto, el incremento de la población, interesa solo si vamos más allá de las cifras que arrojaba su recuento: las muchas familias que comienzan a ser «contabilizadas» en los diferentes distritos y por distintos agentes (sus curas párrocos, sus jueces próximos) dejan de ser meros habitantes para convertirse en «una población». Deseable o indeseable (como en el caso de «los perjudiciales»), se convierten en sujetos políticos y objetos de políticas, en gobernados que, se verá, quieren aspirar también a ser gobernantes.

\section{Grandes EXTENSIONES, PEQUEÑOS RECURSOS}

Para los proyectos imperiales de todos los tiempos, las grandes extensiones constituyeron una gran tentación y un serio problema: para una monarquía agregativa en fase expansiva, como puede caracterizarse a la hispánica del siglo XVI, la incorporación de la «provincia gigante» del Paraguay significaba tanto un evidente orgullo de cartografía imperial como un desconcertante desafío para sus técnicas de gobierno. La extensión descomunal era para sus habitantes nativos un espacio conocido, lo cual suponía dificultades para el proyecto de conquista, colonización y evangelización que implicaba, verbi gratia, occidentalizar políticamente estos espacios. Las poblaciones nativas, aunque agrarias y más o menos sedentarias, se movían al ritmo de su relación con el ambiente, con los otros pueblos, del agotamiento de los nichos o de la dinámica del clima o de las guerras. La política hegemónica fue «reducirlos», ponerlos en «policía», práctica que provenía de una experiencia de siglos. El modelo político católico castellano enfrentó este problema con las herramientas que tuvo, haciéndolas más o menos permeables a los contextos, según las posibilidades y las negociaciones que forzaron los agentes nativos ${ }^{29}$. El problema trascendió el carácter nativo de los «gobernados», persistiendo cuando esta población se constituía enteramente de cristianísimos vasallos criollos o de «indios amigos» que habían dejado de formar parte de los «infieles». ¿Cómo gobernar poblaciones dispersas en dimensiones impensables?

Desde una perspectiva sensible a las relaciones entre espacio y tecnologías de gobierno o instituciones de justicia ${ }^{30}$, la relación entre la extensión física del territorio, la distribución de la población y el ejercicio de la jurisdicción

29 Por ejemplo, cfr. los modelos reduccionales en México, el área yucateca, el Perú o el Paraguay.

30 Cierta producción devino inspiración para colegas de todo el orbe. Hespanha, 1990; 1993. Desde la historia del derecho, Métairié, 2004. Costa, 2013. 
se advierte que el problema está presente en casi todos los cuerpos legislativos de tradición judeocristiana ${ }^{31}$. Puede rastrearse en el Derecho Romano, y la Monarquía hispánica (entre otras) tradujo a su propio lenguaje de gobierno muchos de los dispositivos que allí se proponían así como otros que tomó de la tradición musulmana. No obstante, la formulación del problema fue variando y durante el siglo XVIII - por el aumento de las poblaciones, por la conflictividad bélica en las fronteras con Portugal y con los «indios infieles», por la expulsión de los jesuitas y, sobre todo por la afirmación del carácter agrícola de estos espacios- la cuestión de la presencia física de los agentes de justicia y gobierno en el territorio adquirió un grado de importancia que hasta entonces no había alcanzado, y su carácter se volvió perentorio.

Entre los argumentos que preceden al nombramiento de jueces rurales y creación de nuevos distritos, el referente a las dimensiones de la jurisdicción (el otro que se repetía era el de los constantes robos de ganados y los asaltos en los caminos) fue señalado desde muy temprano como principal obstáculo para el buen cumplimiento de la vigilancia en las campañas: aparece en la normativa y se expresa localmente a través de la pluma de los afectados durante más de un siglo. Se aseguraba, por ejemplo, que la «dilatada extensión» favorecía las «astucias» de los indígenas y la elusión de los ataques militares preparados por los vecinos ${ }^{32}$. En 1790 aparece en la solicitud que José Seguí (alcalde de la hermandad de Paraná) hace al cabildo santafesino antes de proponer el nombramiento de comisionados para distintos parajes de su partido $^{33}$. En 1797, el alcalde de la hermandad de Coronda se quejaba de la distancia que había desde su lugar de residencia hasta el paraje de los Desmochados (bajo su jurisdicción), describiéndola además de una manera muy expresiva: Pedro Reyes consignó que la extensión era de «quince leguas y varias poblaciones» ${ }^{34}$.

En la expresión de los agentes de la época, dimensión (amplitud relativa en función de las tecnologías de gobierno) y distancia (contenido de un trayecto, recorrido posible en función de tecnologías de desplazamiento) guardaban correlación directa con la «insuficiencia» de los alcaldes de la hermandad para «cubrir» el territorio de su jurisdicción -lo cual era, claro está, un horizonte utópico-. Las quejas provenían de los «vecinos de la campaña», quienes denunciaban repetidamente desórdenes y robos de ganados que no

31 Barriera, 2013a.

32 AGSF, AC, tomo VII, fols. 48-49, 10 de noviembre de 1710.

33 Ibidem, tomo XVI A, fol. $35 \mathrm{v}-37 \mathrm{v}$.

34 Ibidem, tomo XVI B, fols. 436-438, sesión del 2 de marzo de 1797. También se lo puede registrar en el cabildo de Buenos Aires durante 1784 o en el de Luján todavía en 1811. 
podían ser prevenidos ni castigados por estos oficiales ${ }^{35}$. Por otra parte, quienes eran objeto de la queja no tenían una versión diferente: varios alcaldes de la hermandad enunciaron dicha insuficiencia en primera persona.

Las razones geo-métricas se combinaban químicamente con una población que los vecinos propietarios y las autoridades -que muchas veces coincidíancaracterizaban «familias vagas» ${ }^{36}$. La expresión, cargada de interés, refiere a la «gente suelta» que se había instalado «sin licencia» en las inmediaciones de las propiedades de los hacendados de Coronda, Salado, Chañares, los Arroyos y «tierras de entre ríos» ${ }^{37}$. Algunos eran indios que abandonaban los pueblos de San Javier, San Jerónimo y San Pedro ${ }^{38}$, pero también mestizos provenientes de Santiago del Estero, Córdoba y Tucumán. Lo cierto es que el incremento de pobladores en el área conllevaba necesariamente estos problemas de proximidad -roces, disputas por recursos, por ubicación, por la antigüedad en el área, incluso si esta era mínima- y la reubicación de los forasteros en la población de la frontera ofrecía una solución que aunaba los intereses de propietarios productores, autoridades de gobierno y jefes de milicias.

\section{ADMINISTRACIÓN Y MICROPOLIÍTICA: LA CREACIÓN DE LAS NUEVAS JURISDICCIONES RURALES}

Los grandes distritos rurales, surgidos del modelo jurisdiccional o «judicial» ${ }^{39}$-un «juez gobernador» sin voz ni voto en el cabildo, era instituido con capacidad de administrar justicia en un territorio descomunal y sobre una población desconocida- ${ }^{40}$ sufrieron en Santa Fe una progresiva subdivisión

35 AGSF, Varios Documentos, 1634-1816, leg. 20, fols. 5v-7, 10 de enero de 1791. Un mes más tarde, el escribano registró que los alcaldes de la hermandad resultaban probadamente insuficientes para contener a la población «desordenada».

36 AGSF, AC, tomo XV, fol. 365.

37 Donde la cosa no era diferente: cuando en 1799 el Juez Comisionado de Nogoyá describió los inconvenientes que encontraba para cumplir con su función, mencionó entre los primeros «la altanería y poca sumisión se aquella gente, los muchos vagabundos y reos que andan en aquel país con toda libertad y desafuero», AGSF, 7 de mayo de 1799, tomo XVI B, fols. $512-513 \mathrm{v}$.

38 He aquí un resultado tangible de la diferente gestión de estos pueblos tras la expulsión de los jesuitas. Véase al respecto, Moriconi, 2014.

39 Mannori, 2007: 125-146.

40 Los alcaldes de la hermandad fueron nombrados desde 1616; desde 1725 se hace referencia al «nombre» del territorio sobre el cual tienen jurisdicción (la Otra Banda uno, Coronda-Los Arroyos el otro). Solo en 1784 se nombró un tercer alcalde de la hermandad para 
sin apartarse del modelo. Hasta 1784, la jurisdicción del Pago de los Arroyos incluía todo el sur santafesino al oeste del río Paraná: desde el Paso de Santo Tomé hasta Arroyo del Medio, su borde oeste lo constituía la línea de fortines y una imprecisa y móvil línea que no se ajustó hasta 1888. Su división en dos en 1784 implicó la designación de un nuevo alcalde de la hermandad para el «partido» de Coronda, cuyo territorio coincidió con el pago de Coronda, así mentado desde finales del siglo anterior y -admitiendo que la jurisdicción eclesiástica conlleva particularidades que no permiten el calco- con el del curato de Coronda, erigido por el obispado de Buenos Aires en 1749. Este partido cercenaba la jurisdicción del de Los Arroyos desde el río Carcarañá al norte, hasta las puertas de la ciudad, en el paso de Santo Tomé41.

Apenas habían pasado cinco años de su creación cuando el partido fue subdividido: el 2 de marzo de 1789, el cabildo designó tres nuevos jueces, denominados pedáneos, de la mano de la creación de tres nuevos distritos: Carcarañá, Arroyo Monje y Chañares, arguyendo que se aligeraba así la carga que pesaba sobre el alcalde de la hermandad de Coronda ${ }^{42}$.

Los capitulares santafesinos describieron el contorno de estos nuevos distritos con bastante precisión: el río Paraná funcionó como el borde oriental de toda la jurisdicción (de hecho, la las tierras al oriente del mismo se denominaron siempre desde Santa Fe «la otra banda») y tres cursos de agua que desembocan en el río Coronda, brazo del Paraná, fueron utilizados para recortar el pago de Coronda en distritos: el de Carcarañá, comprendido entre la ribera norte del río homónimo ${ }^{43}$ hasta la banda sur del Arroyo Monje; desde la banda norte de este arroyo hasta el sur del Colastiné (incluyendo el «lugar de Resquín») se extendía el nuevo distrito de Arroyo de Monje y, por último, el distrito de Chañares quedaba delimitado entre el paso de Santo Tomé (vado del río Salado al sur de Santa Fe) hasta poco más de una legua al oeste de la ciudad de Santa $\mathrm{Fe}^{44}$. De este modo, el territorio «restringido» a cargo del alcalde de la hermandad de Coronda -aunque como pago seguía conteniendo a estos tres- se consolidaba entre la banda norte del Colastiné y el sur del

dividir un territorio, el de Coronda-Los Arroyos que superaba en superficie (no en ocupación ni en conocimiento del mismo) el millón de hectáreas.

41 Sobre el período anterior y las complejas relaciones entre las jurisdicciones seculares y eclesiásticas remito a Barriera y Moriconi, 2015.

42 AGSF, AC, tomo XV B, 2 de marzo de 1789, fols. 352v-354. En Córdoba el número de pedanías llegó a 84. Allí los designaba el subdelegado, marqués de Sobremonte, desde 1783.

43 La del sur correspondía al inicio del pago de los Arroyos, o «del Rosario», que se extendía desde allí hasta el Arroyo del Medio.

44 AGSF, AC, tomo XV B, 2 de marzo de 1789, fol. 353 v. 
Paso de Santo Tomé, comprimiéndose sensiblemente la superficie geométrica del orbe a cargo del alcalde partidario.

La creación de distritos a cargo de jueces pedáneos en 1789 fue la primera medida que se tomó para auxiliar a los alcaldes de la hermandad asociada con una preocupación por delimitar los contornos territoriales del alcance de la vara: por primera vez no se designaban comisionados para una tarea específica, sino judicaturas vinculadas con un territorio y su población. De cualquier modo, aunque se delinearon puntos de referencia, la designación del hombre con capacidad delegada para administrar justicia era todavía preeminente frente a la sensibilidad por determinar un contorno territorial que permanecía más o menos abierto al oeste, a causa de la movilidad indígena y de las permanentes invasiones de vecinos de otras jurisdicciones. En la relación jurisdiccional, para la población todavía era más importante «el juez-gobernador» que el territorio y que las leyes mismas.

Sin embargo, para hacer un análisis micropolítico, más que las decisiones que se tomaron lo que nos interesa es cómo fue el proceso que llevó a la toma de estas decisiones. Para eso es preciso tirar del hilo que propone la primera subdivisión del partido de Coronda.

A finales de 1788, los vecinos del flamante partido hicieron llegar al virrey-intendente una carta donde ofrecían financiar la erección de una pequeña villa a orillas del Arroyo de las Ovejas (ubicado 34 leguas al norte de Santa Fe) así como el traslado de unos «perjudiciales» para poblar dicho establecimiento, que pretendían hacer coincidir con el traslado del fuerte de San Juan Bautista, proyecto que el cabildo alentaba desde hacía unos pocos años ${ }^{45}$. Lo hicieron a través del procurador síndico general del cabildo, Juan Francisco de Larrechea, quien había asumido el cargo a comienzos de ese mismo año. El nombre, como se verá pronto, importa.

El 12 de febrero de 1789, el virrey Loreto ${ }^{46}$ vio el expediente e hizo dos cosas: mandó una providencia al cabildo de Santa Fe y remitió una copia del expediente al comandante de armas de Santa Fe, autoridad militar bajo su dependencia directa. Al comandante le pidió su opinión acerca del pedido que implicaba la "“representación" del vecindario de Coronda» y, en caso de «adoptarse los establecimientos propuestos», quería conocer cuáles serían los

45 En 1786, el cabildo había solicitado trasladar allí el fuerte de San Juan Bautista. Archivo General de la Nación, Buenos Aires (AGN), IX-24-1-7.

46 Nicolás Felipe Cristóbal del Campo y Rodríguez de Salamanca (1725-1803), segundo marqués de Loreto, virrey del Río de la Plata entre 1784 y 1789. 
medios más adecuados para el «maior fomento de las poblaciones» ${ }^{47}$. Al cabildo le ordenó que -ya que los vecinos de Coronda se ofrecían «...expontaneamente a contribuir con carruajes y algunos ganados a dicho objeto»- se encargara de formar una lista de los hombres que querían sufragar esos gastos. También le ordenó nombrar jueces pedáneos

... para que no carezcan aquellas campañas de juezes pedáneos que vigilen y contengan los robos e insultos que se experimentan, concedese al Cavildo de Santa $\mathrm{Fe}$ la facultad de nombrar, «por ahora, tres sujetos» de celo y probidad en clase de tales juezes pedáneos que exerceran [v] su comision «en los tres distritos que propone el Procurador» en su informe hasta que otra cosa se mande ${ }^{48}$.

El cabildo obró en consecuencia: comisionó al alcalde de la hermandad de Coronda para formar una lista con los vecinos del partido que habían ofrecido los recursos para enviar a Las Ovejas a «...toda aquella gente perniciosa en su partido, y que no tienen establecimiento propio en él ni haciendas bastantes con que mantenerse ${ }^{49}$ y dispuso por vez primera el nombramiento de jueces pedáneos sin que esto significara el cese del nombramiento del alcalde de la hermandad (cuya tarea debían aliviar) ni de comisionados. Entonces, la designación de estos tres nuevos jueces y la creación de tres nuevos distritos (Carcarañá, Arroyo Monje y Chañares) fue realizada por el cabildo después de una «providencia» del virrey, pero a propuesta del procurador, portador de la voz (la «representación») de los vecinos-hacendados de Coronda. Estos fueron finalmente quienes sugirieron la creación de las nuevas judicaturas y acabaron por proponer los nombres a través del alcalde de la hermandad y el comandante de armas.

Tanto la división del pago de los Arroyos como la subdivisión del partido de Coronda tienen en común el haber sido «autorizadas»-no decididas, ni impulsadas, ni motorizadas- por el gobernador-intendente ${ }^{50}$. El mediador que había canalizado el pedido de los vecinos en su calidad de procurador de la

47 AGSF, Notas y Otras Comunicaciones (en adelante, NyOC), II, fol. 209. El énfasis es mío.

48 AGSF, NyOC, II, fols. 209 y 209v., los énfasis son míos.

49 AGSF, AC, tomo XV, fols. 352-354. Ferreyra (2003: 102) vinculó las contribuciones y este pedido con un proyecto de expulsión de «perjudiciales» que forma parte de una verdadera lista de proyectos de deportación de vagos y perjudiciales.

50 AGSF, AC, tomo XV, 24 de diciembre de 1783, fols. 112-113. Lo mismo sucedió en julio de 1790, ante la «urgente necesidad de crear Jueces Pedáneos para Paraná, Rincón y Ascochingas» (AGSF, AC, tomo XVI A, fols. 78-80). En el fol. 111 se nombra al intendente por el título completo, Sr. «Intendente General de Ejército y Real Hazienda», nombrando la jurisdicción a su cargo como «...una Superintendencia General de Real Hazienda». 
ciudad, conocía bien el pedido de estos «vecinos» de Coronda (luego hicieron lo propio algunos del Salado, de Chañares, del Pago de los Arroyos y de las «tierras de entre ríos») que tenían chacras o estancias pero que además, «vivían» en ellas y no en la ciudad. El virrey «facultó» al cabildo para nombrar tres jueces pedáneos, «que vigilen y contengan los desórdenes» en los distritos propuestos por el procurador general ${ }^{51}$.

\section{LAS INSTITUCIONES Y LOS AGENTES}

Un aspecto clave de la creación de estas pedanías fue su carácter no excluyente: al contrario de la erección de los nuevos curatos o de nuevas alcaldías de la hermandad, en cuyos casos la nueva jurisdicción, secular o religiosa, era segregada de una mayor preexistente, el nombramiento de pedáneos a partir de 1789 no recortaba la jurisdicción a los alcaldes de la hermandad ${ }^{52}$. Estos podían contar con ellos como auxiliares y además conservaban jurisdicción sobre los mismos territorios, sin perder el derecho a nombrar cuadrilleros -ayudantes armados para hacer cumplir medidas-, realizar detenciones (imponer su autoridad) a los cuales podían designar coyunturalmente y siempre a su costo y cargo. La condición de los pedáneos como «auxiliares» de justicia se deja ver en el nombramiento de 1789 y se consolida en el de 1797, cuando fueron designados como «jueces auxiliares o pedáneos de los alcaldes de la hermandad $»^{53}$. Idéntica importancia tiene el hecho que los alcaldes de la hermandad tuvieran influencia en la selección de los pedáneos para los distritos comprendidos en su jurisdicción, ya que el cabildo los comisionaba para hacer la lista de los hombres aptos para el oficio. Su propuesta, no obstante constituir un paso obligado ${ }^{54}$, quedaba sujeta a la aprobación del cabildo.

${ }^{51}$ AGSF, AC, tomo XV B, fols. 348-352v, cfr. con el informe del procurador Juan Francisco de Larrechea.

52 La relación entre los alcaldes partidarios y sus auxiliares fue en general de colaboración, aunque no faltaron los conflictos productos de celos o choque de intereses. En ciertos casos, los roces exigieron intervenciones que aclaraban la situación de los unos y los otros.

53 AGSF, AC, tomo XVI B, 16 de enero de 1797, fol. 435.

54 El pedáneo de Nogoyá no se designaría hasta que llegara el informe del Alcalde de la Hermandad del Paraná, AGSF, AC, XVI A, 15 de enero de 1793, fols. 176-177; en enero de 1796 se dispuso la elección de los jueces pedáneos, con excepción del partido de Coronda que se reservó para cuando compareciera el alcalde de la Hermandad electo (AGSF, AC, XVI B, 7 de enero de 1796, fols. 345-347v); Pedro Reyes, alcalde de Coronda, a la hora de designar un sustituto, recomendó a Mariano Baigorri y ante la necesidad de un pedáneo para Desmochados (por la distancia y los poblados) propuso a Agustín Lucena. El Cabildo accedió. AGSF, AC, XVI B, 2 de marzo de 1797 fols. 436-438. 
Es evidente que componían las ternas con nombres de su confianza y que el orden que llevaban sugería la preeminencia que pretendía; regularmente el primero de la lista fue designado sin discusión, pero en ocasiones, el orden fue motivo de objeciones ${ }^{55}$.

Todo esto tiene su importancia a la hora de concebir teóricamente el gobierno de los campos: veamos el caso de Coronda con nombres y apellidos.

1) El procurador que llevó al virrey la «representación» de los vecinos de Coronda donde se proponía la expulsión de los perjudiciales, el financiamiento de su traslado al Arroyo de las Ovejas, la división del territorio y la creación de las tres nuevas judicaturas para idéntico número de distritos en 1788 era Juan Francisco de Larrechea, que se desempeñaba como Sargento Mayor de la Plaza y había aceptado nuevamente esa carga (la de procurador), rechazando continuar también como juez de menores - por encontrar que había incompatibilidad entre las mismas--. Además, arguyó que la procuraduría le consumía un tiempo que no le sobraba, puesto que también se desempeñaba como miembro de las juntas de Propios y arbitrios y de Temporalidades ${ }^{56}$.

2) Esta es la nómina de los vecinos-hacendados de Coronda que llevó al virrey Juan Francisco de Larrechea: el capitán de milicias Fernando Méndez, Pedro de Gaviola, Ignacio de la Cruz (Suero), Ramón Aguilera, Bernardo Romero, Domingo Correa, Juan Francisco de los Ríos, Domingo de los Ríos, Manuel Antonio Zavala, Manuel Torres, José Zeballos, Ignacio Martínez, Juan José Redruello (maestro de reales postas), el sargento Juan Segundo Ortíz de Vergara, el presbítero Malaquías Duarte Neves, Gabriel de Lassaga, Manuel de Toro y Villalobos, Francisco Solano Frutos y Martín Francisco de Larrechea (su hermano) ${ }^{57}$.

3) Desde la creación del partido, se habían desempeñado como alcaldes de la hermandad de Coronda Ignacio de la Cruz Suero (1784), Cayetano de Torres (1785), Manuel Antonio Zavala (1786), Jacinto de Vergara (1787), José Miguel de Retolaza o Retolosa (1788) y Domingo Alarcón (1789). Para las primeras judicaturas menores (pedanías) creadas en 1789 los designados fueron Francisco de la Cruz Suero (para el distrito del Carcarañá), Julián Alzugaray (para el distrito de Arroyo del Monje) y Martín Francisco de Larrechea (para el de Chañares).

Como se ve en la instantánea -omito aquí las largas historias de cada uno de ellos, que no hacen más que sumar anos de desempeño en diferentes oficios y tareas vinculadas con el gobierno, años antes y después de esta coyuntura-,

\footnotetext{
55 Barriera, 2012.

56 AGSF, AC, tomo XV B, fol. 255, sesión del 7 de enero de 1788.

57 AGN, IX-24-1-7, exp. 6.
} 
los vecinos-hacendados ocuparon estas bajas magistraturas rurales. Pero lo hicieron en primera persona o a través de sus familiares y, por lo demás, no fue el único espacio que controlaron.

4) De la lista de los vecinos que peticionaron ante el virrey a finales de 1788 se ve que, en lo inmediato, Ignacio de la Cruz Suero, Manuel Antonio Zavala y Martín Francisco de Larrechea ocuparon inmediatamente bajas magistraturas. Pero el resto también se insertó en diferentes segmentos de la trama de las actividades políticas rurales y en distintos momentos, no muy lejanos.

El capitán Fernando Méndez aportó seis novillos a la expulsión de los perjudiciales. No he podido encontrar su propiedad ni actividades económicas, pero los archivos parroquiales permiten documentar que no se trata de un militar venido de «afuera» sino de un hombre arraigado en el lugar. El 2 de diciembre de 1764, con motivo de la visita del obispo de Buenos Aires Dr. Manuel Antonio de la Torre, tomaron la confirmación en la capilla de San Jerónimo de Coronda sus hijos Rosa, Guillermo y Ramón (todos habidos de su matrimonio con Josefa Basualdo $)^{58}$. Los libros de matrimonio de la misma parroquia registran también el casamiento de dos de sus hijos (José en 1799 y Nicolasa en 1800), y allí lo sindican como capitán reformado y «del partido». Sus hijos tuvieron por padrinos de casamiento a Domingo Alarcón (el alcalde de la hermandad de 1788) y su esposa, Severina Méndez (hermana de Fernando), lo cual los convierte además en cuñados. Fernández Méndez falleció antes del matrimonio de Nicolasa, donde se lo evoca como «difunto» ${ }^{59}$.

5) Pedro de Gaviola es hijo de Manuel Gaviola (un activo miembro del cabildo santafesino y propietario de tierras en el sur desde mediados de la década de 1750) que en 1766 había adquirido nada menos que el título de alcalde provincial de la santa hermandad ${ }^{60}$. María Polonia, su hermana, contrajo matrimonio con otro de los vecinos firmantes de la «representación», Manuel de Toro y Villalobos, de quien por lo tanto Pedro devino cuñado. Cuando Toro testó en 1796 - con gran generosidad para los conventos de la ciudad- afirma que antes de casarse tanto él como su mujer ya eran propietarios de tierras en Coronda, «lindero de los Oroño» ${ }^{61}$.

58 Archivo de la Parroquia de San Jerónimo, Santa Fee, Coronda, Confirmaciones, vol. I: 1747-1764.

59 Ibidem, Libro de Matrimonios de Coronda, pássim.

60 AGSF, AC.

61 Ibidem, suplemento 1796-1811, fol. 3 . 
Este Manuel del Toro no era pobre y no era solamente un campesino: había sido procurador de la ciudad en 1778, alcalde del crimen en 1781, 1784, 1786; alcalde de primer voto en 1787, y en 1791 sustituyó a Aldao en la procuraduría. En 1794, el año anterior a su deceso, volvió a ser alcalde de primer voto. Entre los papeles que dejó al morir se contaban derechos sobre deudas de terceros que incluían a su suegro, también ya difunto, Manuel Gaviola.

Volviendo a Pedro, quien contribuyó fuertemente para la expulsión de los perjudiciales con 25 reses y carretas, fue un conspicuo ganador de los remates de los diezmos de cuatropea, convirtiéndose en administrador sobre los de los curatos de Paraná (en 1770), del curato de los Arroyos (1779, 1781, 1786) y los del curato de Coronda $(1781,1783)$. Mención aparte amerita su inversión de 1787, el año anterior a la representación, cuando se adjudicó los de cuatropea de Paraná y, sobre Coronda, el de granos además del de cuatropea ${ }^{62}$.

6) Los Larrechea tienen mucho que ver con la historia de este territorio, y por eso no llama la atención que ocupen un lugar destacado en este entuerto. Juan Francisco (el procurador que portó la «representación» ante el virrey) fue alcalde de segundo voto en 1767 y de primero en 1777 y 1783 (años más tarde volvió a serlo en 1804). Martín Francisco -su hermano- fue alcalde de segundo voto de Santa Fe en 1776, procurador en 1780, y en 1788 era sargento mayor de la plaza, síndico procurador general y defensor de pobres y menores. Su presencia en Buenos Aires gestionando el pedido de los vecinos de Coronda coincidió - podemos presumir que no casualmente- con el momento en que toma contacto con la causa de filiación que le había iniciado recientemente en esa ciudad un hijo natural (José Francisco) habido con una mujer «española» (María de la Rosa) en Santa Fe en 175963. Juan Francisco compró los remates del diezmo de cuatropea de Los Arroyos y Coronda en 1759, el de granos de Coronda en 1765 y el de cuatropea de Paraná en 1772.

${ }^{62}$ AGN, IX-13-3-3. Agradezco a Julio Djenderedjian el haberme facilitado su transcripción organizada e informatizada.

63 El poder está otorgado en Buenos Aires el 5 de noviembre de 1788. El hijo lo había hecho aparentemente como paso previo a poder participar en la vida pública: «...por mí y en mi nombre y representando mi propia persona como si presente fuere y como yo mismo haría ante los señores jueces ordinarios de aquella ciudad produzca información en devida forma que acredite los Padres de que procedo como el de ser estos de calidad españoles, limpios de toda mala raza y que por consiguiente por parte de mi nasimiento soy apto para obtener qualesquiera honores y empleos que se me confieran haciendo para ello los pedimentos necesarios que presente con los escritos y documentos que conduzgan a este fin y sean necesarios sacándolos del poder de quien los tubieze...», Departamento de Estudios Etnográficos y Coloniales, Santa Fe, Expedientes civiles, tomo XLI, leg. 515, fol. 679. 
Martín Francisco, por su parte, se hizo de los diezmos de cuatropea de Los Arroyos y Coronda en $17744^{64}$.

7) Domingo de los Ríos también fue recaudador. En 1763 fue el recaudador del diezmo de cuatropea en los tres pagos y en 1769 el de granos en Coronda. Lo mismo hizo Redruello, quien además de maestro de las reales postas recaudó diezmo de granos en Los Arroyos (1768 y 1772), y granos en Coronda (1784, 1790, 1792, 1793 y 1794).

Puede continuarse, pero vemos ya claramente que el alcalde de la hermandad era compadre del capitán de milicias, el hijo de un ex alcalde provincial devino un frecuente comprador de los remates de diezmos de la zona, su hermana se casó con otro propietario con activa participación en el cabildo a pesar de sus estancias en el campo. Por lo demás todos ellos formaban parte de los propietarios y productores de Coronda, desarrollaron actividades económicas en el lugar y fueron los que pensaron el modo de subdividir y gobernar un territorio al que le ponían el cuerpo ${ }^{65}$.

\section{CONCLuSiones}

La subdivisión de los territorios vinculados con alcaldes de la santa hermandad no afectó solo a Coronda y no terminó en 1789: esas coordenadas señalan el comienzo de un proceso de miniaturización del territorio en la jurisdicción santafesina, a una y otra banda de los ríos Paraná y Salado. En enero de 1791 se designaron pedáneos dentro de cada uno de los tres grandes pagos (Coronda -lo visto- los Arroyos y la Otra Banda): con el nombramiento de jueces auxiliares en Ascochingas, Desmochados y Nogoyá, el Cabildo desnudaba cómo la disminución de la escala física del territorio a guardar -motivo explícito para argumentar el aumento exponencial de jueces en el período- no solucionaba el problema. Aunque los distritos de estos pedáneos eran menores que los pagos de un alcalde de la hermandad, y menores aún que los distritos de sus pares nombrados apenas dos años atrás, se habían creado porque los auxiliares de 1789 esgrimieron, intactas, las problemáticas que afectaban a los alcaldes de la hermandad de mediados de los años 1780: los territorios, aunque físicamente eran cada vez más pequeños, seguían sien-

64 AGN, IX-13-3-3.

65 De todos puede decirse más: Manuel Torres también era productor. El nieto de doña Beatriz Gómez Recio criaba caballos y tenía una chacra en Coronda, que hacía trabajar: con frente de una legua al Salado y fondo a la «cañada del Carrizal» -hoy Carrizales-, AGN, IX23-4-6, exp. 110. 
do considerados inabarcables por los hombres que debían guardarlos y, en consecuencia, ellos seguían manifestando que necesitaban reducir el tamaño del terreno y obtener apoyo de auxiliares, preferentemente armados.

El 18 de abril de 1789, el alcalde de primer voto de Santa Fe solicitó al Comandante de Armas que ordenara a las Milicias de la campaña brindar el auxilio necesario a los flamantes jueces pedáneos. En 1791, el Cuerpo -quizás recordando la solicitud de Larrechea, cuando condicionó al suministro de cuatro blandengues su aceptación a la pedanía de Chañares en 1789- resolvió designar auxiliares para los pedáneos antes de que se los pidieran ${ }^{66}$.

El proceso de miniaturización del territorio mostraba los mismos problemas en escalas cada vez más reducidas. Lo que no se verifica en ningún caso, y es importante insistir en esto, es el despliegue de nada que se parezca a un aparato del estado que, "desde arriba», organizara el mundo rural como si se tratara de una tabula rasa. Las divisiones territoriales de finales del siglo XVIII en una región de cultura política sufragánea muestran, al contrario, que las mismas surgieron desde la relación cara a cara de lo que podríamos denominar los grupos intermedios -bajas élites urbanas y vecinos rurales que son propietarios, ganaderos y recaudadores del diezmo.

En el panorama rioplatense de la época, Santa Fe no era una excepción. Compartía el contexto económico, social y político con otras ciudades del virreinato. Sin embargo, el nombramiento de auxiliares de justicias y la creación de nuevos distritos territoriales fue un proceso que, respecto de Buenos Aires, Córdoba o Mendoza, se presentó algo tardíamente. Probablemente esto haya incidido en su carácter híbrido, permitiendo tomar distintos tramos de experiencia de aquí y allá.

La designación de jueces menores asociados a un distrito de manera permanente era novedosa, pero no se «recortaban» de las jurisdicciones superiores. Estamos en presencia de un proceso de miniaturiazación sin autonomización. Desde lo institucional y jurisdiccional, los pedáneos y los comisionados tenían capacidad judicial en parajes, territorios más o menos delimitados, donde se iba asentando población cada vez más estable, sujetos a las decisiones del alcalde de la hermandad y también al gobierno de la ciudad. Las nuevas jurisdicciones, que eran tres en 1789 y superaban las cuarenta en 1804, se asociaron a distritos delimitados por marcas paisajísticas propias del litoral $\mathrm{o}$, en ocasiones, por marcas que son huellas sociales (lugares conocidos por

66 «Y en razón de que los Jueces Pedáneos respectivos no pueden atender su distrito, se designan los siguientes Comisionados...», AGSF, Varios Documentos: 1634-1816, leg. 20, 10 de enero de 1791, fols. 5-7. 
permitir el paso del ganado; por haber estado allí alguna reducción o alguna estancia; parajes recortados de la propiedad de algún antepasado «célebre»).

Los vecinos que ejercieron estas judicaturas menores desde 1789 residían a tiempo parcial o a tiempo completo en las unidades productivas que tenían en los distritos donde se los nombraba. El tipo de vecindad que ejercían no dependían de una norma... derivaba del reconocimiento de la comunidad. Por una parte podría pensarse que lo obtenían porque los hijos de vecinos de la ciudad, cuando se iban al campo, portaban con ellos la «vecindad». Pero la experiencia de los vecinos sugiere pensar en una dinámica de reconocimiento comunitario: es decir, eran «vecinos» aquellos que eran reconocidos como tales por otros o aquellos que conseguían ser reconocidos como tales por las autoridades de turno. Esto, como lo ha sugerido Tamar Herzog para toda la monarquía, estaba claramente atado a «...un común acuerdo sobre lo que significaba la existencia de la comunidad política» ${ }^{67}$.

Los pequeños propietarios de Coronda gestionaban sus haciendas y se involucraban físicamente con la actividad judicial en el territorio (que implicaba gobernarlo) porque se encontraban en el contacto «cara a cara» con las poblaciones «perjudiciales» (que lo eran sobre todo para sus actividades económicas ligadas a la producción agropecuaria) y, como resulta evidente del petitorio elevado en 1788, pretendían terciar físicamente en el proceso de inclusión y exclusión de pobladores de su zona. La práctica de la coacción por parte de los jueces-hacendados sobre los cuerpos de los «perjudiciales» era un secreto a voces, al punto tal que se aceptó que cargaran con el financiamiento de los apoyos que pedían. La situación se reiteró en varias ocasiones: en 1800, el virrey Avilés, consultado sobre el modo en que debían costearse las milicias y la forma en que podía prestarse apoyo armado a ciertos jueces comisionados que decían no tener «fuerza» para aplicar sus justicias, respondió al cabildo santafesino que, en tanto los principales interesados en «el exterminio de ladrones» eran los hacendados del lugar, ellos mismos debían componer un fondo para pagar a las milicias que requirieran ${ }^{68}$.

Estos vecinos de la campaña santafesina (el de Coronda obviamente no fue el único caso, también lo hicieron los del Salado y de varios parajes en la otra banda) supieron formular el modo en que querían organizar la vida política de sus territorios aprovechando los canales formales de comunicación política que les ofrecía una coyuntura precisa, tanto como midiendo los momentos precisos para tener una interlocución casi directa con el virrey-gobernador. Que el hermano más «citadino» de uno de ellos ocupara la procuradu-

\footnotetext{
67 Herzog, 2000: 127.

68 AGSF, Expedientes Civiles, CXLIX, 26 de mayo de 1800, fols. 33-34.
} 
ría del cabildo no podía desaprovecharse. La presencia de los hermanos Larrechea en el campo y en la procuraduría al mismo tiempo permitió al grupo canalizar muy directamente sus reclamos, combinando saberes y posiciones. Esta organización, de la cual el caso de la subdivisión del partido de Coronda es una muestra, no ocurría como ya se dijo bajo la forma del despliegue de una estructura en estado germinal, genéticamente pre-existente; tampoco era algo querido solamente por las autoridades. Los nuevos jueces rurales, aunque pueden considerarse genuinamente un producto del reformismo, no eran sin embargo el efecto de una reforma pensada «desde arriba». Al contrario, su puesta en escena, así como la aparición de múltiples nuevos distritos que subdividían las viejas jurisdicciones sin amputarlas, fue el resultado de un interés coincidente entre pobladores prácticos y funcionarios del gobierno intendencial que no habían previsto su designación entre las medidas que formaban parte de su propedéutica.

Siguiendo la inspiradora metáfora de Antonio Manuel Hespanha, para convertir a la extensión bruta en un espacio organizado era preciso acortar las distancias en dos sentidos: físico y relacional. Los jueces de los campos no eran «jueces de afuera», como en la tradición portuguesa o en la primera tradición hispánica de los corregidores o alcaldes de la hermandad. La ciudad dejó de comportarse como un centro que enviaba «vecinos a lo lejos» y el virrey, consultando con su comandante de armas y respetando el vínculo de las comunidades rurales con sus cabildos, dotó de capacidades judiciales y de más o menos precisos contornos de un distrito a esos hombres que, residiendo en el campo, eran vecinos de esos pagos. Allí, ellos eran próximos: conocían el lugar, conocían su población, sus problemas y sus lenguajes. Pedáneos y comisionados eran arraigados para los recienvenidos; para los convecinos, pares de los que podían esperar protección, indiferencia o revancha, pero con los cuales siempre podían negociar porque eran corresidentes; para los subalternos sueltos e infamados, persecutores y, para sí mismos, jueces. Investidos de una vara cuyo valor simbólico era harto distante del rudo ejercicio de su autoridad real, fueron de pronto gobierno y justicia menor en distritos que siempre eran más anchos de lo que hubieran pretendido.

La Real Ordenanza de Intendentes ${ }^{69}$ aludía al gobierno de los campos con la estructura clásica de un Provincial de la hermandad con sede en el cabildo, con más los alcaldes de la hermandad y sus «cuadrilleros» patrullando las campañas, por lo cual los agentes interesados en solucionar el problema localmente no encontraron en la letra de este instrumento un modelo alternati-

69 Me refiero siempre a la Real Ordenanza para el establecimiento e instrucción de Intendentes de Ejército y Provincia en el Virreinato de Buenos Aires, del 28 de enero de 1782. 
$v^{70}$. Frente al desafío de organizar unos entornos rurales en plena transformación demográfica, económica y social, la existencia de diferencias locales a la hora de crear las necesarias judicaturas rurales de proximidad se explica en parte, justamente, por esa ausencia de prescripciones concretas sobre el tema en la Real Ordenanza de Intendentes ${ }^{71}$. Este instrumento, muy puntilloso en lo que concierne al gobierno de los grandes territorios, en materia de organización del gobierno y vigilancia en el interior de las ciudades, pródigo en la creación de contralores sobre altos funcionarios ${ }^{72}$ y expresivo de un celo notable en materia de control de las haciendas y hasta de las autonomías de los municipios ${ }^{73}$, dejó en cambio a los cabildos y a los vecinos las manos libres para proponer sus propios modos de organizar el gobierno de los campos. No cabe ninguna duda de que la designación de pedáneos y comisionados así como la creación de nuevos distritos no respondió a la aplicación de ningún capítulo de la Real Ordenanza de Intendentes. El cabildo no fue obligado a nombrar jueces por ninguna autoridad superior. Bien al contrario, el circuito comunicacional que precedió a la designación de pedáneos y comisionados muestra que fueron los «vecinos-hacendados» y las propias familias asentadas (las que podían esgrimir propiedad, vecindad y continuidad territorial) las que promovieron estas designaciones. Como se observa por los motivos que originan la correspondencia donde se solicita y se discuten las creaciones de empleos de pedáneos y comisionados, su motivación no proviene del impulso reformista de los Borbones ni de la letra de la Real Ordenanza de Intendentes, sino de las «necesidades» que los vecinos atravesaban en las campañas, la cual supieron comunicar a través de la pluma de sus intérpretes.

Esto, sin embargo, no implica que la administración borbónica no tuviera planes o no quisiera ejercer su peso sobre los cabildos: al contrario, a partir de 1791 se ve perfectamente una clara intención de parte del Virrey (cabeza también de la gobernación-intendencia de Buenos Aires) de participar activamente en las decisiones sobre el tema del cabildo -se reserva el nombramiento de los jueces de campo- $\mathrm{y}$ vecinos (influyentes y no) que lo ubican rápidamente como un interlocutor receptivo a sus demandas. Después de 1791,

70 Esto ya fue señalado para Tucumán por Tío Vallejo, 2007.

71 La hipótesis de Silvia Romano va en el mismo sentido: para la autora, en Córdoba, la figura del juez pedáneo había sido «jerarquizada por Sobremonte y puesta bajo su órbita para reforzar el control social y el poder de la autoridad política sobre la sociedad en su conjunto, fue mantenida durante el proceso revolucionario pese a que la figura del pedáneo se había desdibujado en la normativa emanada del poder central». Romano, 2010: 184.

72 Sobre el particular remito a los trabajos recopilados en el ya citado libro de Mariluz Urquijo y al más reciente de Abásolo, 2005.

73 San Martino de Dromi, 1992. Tau Anzoátegui y Martiré, 2005. 
el Virrey señaló sistemáticamente su preeminencia sobre el cabildo en materia de designaciones de oficios; pero, recuperando lo mejor del estilo de los Austrias, también dejó hacer y legisló sobre el hecho consumado cuando éste no iba en contra de los intereses de la monarquía. Como en los inicios de la conquista, los intereses de una Monarquía distante y percibida como centralizadora podían coincidir con los de medianos y pequeños hacendados activos dispuestos a asumir el gobierno de sus tierras. La sinergia entre ambos agentes juntó filas en el territorio y sumó renglones en un proceso de institucionalización que integró apetencias convergentes.

El análisis micropolítico de las informaciones e influencias que subyacen a la creación de las tres pedanías de 1789 apoya la tesis de una institucionalidad legal y legítima que no deriva de la fría aplicación de leyes sino de una construcción consensual comunitaria a partir de intereses coincidentes entre pobladores, cabildo y virreinato: las leyes se incluyen como elemento del juego, pero el juego las excede. Este proceso no fue provocado en Santa $\mathrm{Fe}$ por la implementación de un modelo «desde arriba» sino que fue producto de la presión de los pobladores-productores involucrados en el proceso de poblamiento del sur en conveniente asociación con el cabildo y con el superior gobierno de Buenos Aires, en quienes encontraron interlocución y coincidente interés en la necesidad de institucionalizar estas instancias. Estos sectores, por último, no son una expresión de «los de abajo», pero tampoco de las élites urbanas: perfectamente podríamos pensarlos como agentes intermedios que, con un pasado y con vínculos en la ciudad, eligieron o fueron puestos a llevar adelante actividades productivas en el campo. Allí se plantaron como productores de granos, recaudadores de diezmos, criadores de animales y eventualmente se convirtieron en jueces menores, mediando sus intereses con el cabildo o con las más altas autoridades del virreinato. Diseñaron territorios apoyados en una experiencia social: un grupo de chacras con sus productores, un paraje con su gente; unas familias alrededor de un oratorio o una capilla contenidas entre dos arroyos fueron el punto de arranque de una vasta extensión transformada en «distrito» (territorio, espacio político) a partir de la experiencia.

\section{BIBLIOGRAFÍA}

Abásolo, Ezequiel, "Estilo militar de gobierno y disciplinamiento en la administración virreinal rioplatense bajo los borbones", Revista de Historia del Derecho, 33 (Buenos Aires, 2005): 13-67. 
Acevedo, E. Oscar, "La causa de policía (o gobierno)", José M. Mariluz Urquijo (dir.), Estudios sobre la Real Ordenanza de Intendentes del Río de la Plata, Buenos Aires, IIHD, 1995: 43-82.

Álvarez, Juan, Historia de Rosario, Rosario, UNR, 1992.

Annino, Antonio, Castro Leiva, Luis y Guerra, François-Xavier (comps.), De los Imperios a las Naciones: Iberoamérica, Zaragoza, Ibercaja, 1994.

Barral, M. Elena, Fradkin, Raúl O. y Perri, Gladys, ‘QQuiénes son los ‘perjudiciales’? Concepciones jurídicas, producción normativa y práctica judicial en la campaña bonaerense (1780-1830)", Raúl Fradkin (comp.), El poder y la vara. Estudios sobre la justicia y la construcción del Estado en el Buenos Aires rural, Buenos Aires, Prometeo, 2007.

Barriera, Darío G., "Instituciones, justicias de proximidad y derecho local en un contexto reformista: designación y regulación de jueces de campo en Santa $\mathrm{Fe}$ (Gobernación-Intendencia de Buenos Aires) a fines del siglo XVIII", Revista de Historia del Derecho, 44 (Buenos Aires, jul.-dic. 2012), en línea.

Barriera, Darío G., "Entre el retrato jurídico y la experiencia en el territorio. Una reflexión sobre la función distancia a partir de las normas de los Habsburgo sobre las sociabilidades locales de los oidores americanos", Caravelle, 101 (Toulouse, 2013a): 133-154.

Barriera, Darío G., "Justicias rurales: el oficio de alcalde de la Hermandad entre el derecho, la historia y la historiografía (Santa Fe, Gobernación del Río de la Plata, siglos XVII a XIX)", Andes, 25 (Salta, 2013b), en línea.

Barriera, Darío G., "Al territorio, por el camino de la memoria. Dos jueces rurales evocan y listan a los habitantes de su jurisdicción y sus actividades económicas (Pago de los Arroyos, Santa Fe del Río de la Plata, 1738)", Mundo Agrario, 30 (La Plata, 2014), en línea.

Barriera, Darío G. y Fradkin, Raúl (coords.), Gobierno, justicias y milicias. La frontera entre Buenos Aires y Santa Fe (1720-1830), La Plata, Edit. de la UNLP, 2014.

Barriera, Darío G. y Moriconi, Miriam S., “Gobiernos y territorialidades: Coronda, de caserío a curato (Santa Fe, Gobernación y Obispado de Buenos Aires, 16601749)", Nuevo Mundo Mundos Nuevos [en ligne], débats, mis en ligne le 10 mars 2015, consulté le 25 mars 2015, http://nuevomundo.revues.org/67858, DOI: 10.4000/nuevomundo.67858.

Birocco, Carlos María, "La pesquisa de Mutiloa en Buenos Aires. Conformación de facciones y lucha por el poder en el cabildo porteño (1700-1715)", Ma. Paula Polimene (coord.), Autoridades y prácticas judiciales en el Antiguo Régimen. Problemas jurisdiccionales en el Río de la Plata, Córdoba, Tucumán, Cuyo y Chile, Rosario, Prohistoria, 2011: 33-56. 
Canedo, Mariana, "Propiedades, propietarios y ocupantes. La tierra y la familia en la campaña de Buenos Aires. El Pago de los Arroyos, 1600-1750", Boletín del Instituto de Historia Argentina y Americana Dr. Emilio Ravignani, III/7 (Buenos Aires, 1er semestre de 1993): 7-29.

Castro Gutiérrez, Felipe, Nueva ley y nuevo rey. Reformas borbónicas y rebelión popular en Nueva España, México, IIH-Colegio de Michoacán, 1995.

Cervera, Manuel María, Historia de la Ciudad y Provincia de Santa Fe 1573-1853, Santa Fe, La Unión de Ramón Ibáñey, 1907.

Cervera, Manuel María, Historia de la ciudad y provincia de Santa Fe 1573-1853, 2da. ed., Santa Fe, UNL, 1908.

Costa, Pietro, "Un spatial turn per la storia del diritto? Una rassegna tematica", Research paper series (Frankfurt, julio de 2013), http://ssrn.com/abstract $=2340055$.

Farberman, Judith, "Los que se van y los que se quedan: familia y migraciones en Santiago del Estero a fines del período colonial", Quinto Sol, Revista de Historia Regional, I (Santa Rosa, 1997).

Ferreyra, Héctor Marcelo, Migraciones forzadas, frontera y conflictos sociales en el sur santafesino: Coronda a fines del siglo XVIII, tesis de licenciatura, UNLU, Luján, 2003.

Garavaglia, Juan Carlos, San Antonio de Areco (1680-1880). Un pueblo de la campaña, del Antiguo Régimen a la "modernidad” Argentina, Rosario, Prohistoria Ediciones, 2009.

García, Lía, "Análisis y determinación de las fuentes para el estudio histórico-demográfico del Pago de los Arroyos, provincia de Santa Fe, Argentina, Siglo XVIII", Dora Celton (coord.), Fuentes útiles para los estudios de la población americana, Simposio del 49. ${ }^{\circ}$ Congreso Internacional de Americanistas, Quito, 1997: 147-164

Herzog, Tamar, "La vecindad: entre condición formal y negociación continua. Reflexiones en torno a las categorías sociales y las redes personales", Anuario del IEHS, 15 (Tandil, 2000): 123-131.

Hespanha, António M., Visperas del Leviatán. Instituciones y poder político. Portugal, siglo XVII, Madrid, Taurus, 1990.

Hespanha, António M., La Gracia del Derecho. Economía de la Cultura en la Edad Moderna, Madrid, CEC, 1993.

Levaggi, Abelardo, "Los alcaldes de la hermandad de Buenos Aires en el período hispánico. Nuevos aspectos", José Luis Soberanes Fernández y Rosa María Martínez Codes (coords.), Homenaje a Alberto de la Hera, México, UNAM, 2008.

Lucaioli, Carina, Los grupos abipones hacia mediados del siglo XVIII, Buenos Aires, Sociedad Argentina de Antropología, 2005. 
Mannori, Luca, "Justicia y administración entre antiguo y nuevo régimen", Revista Jurídica, 15 (Madrid, 2007): 125-146.

Mariluz Urquijo, José María (comp.), Estudios sobre la Real ordenanza de intendentes del Río de la Plata, Buenos Aires, INHID, 1995.

Métairié, Guillaume, La justice de proximité. Une approche historique, Paris, PUF, 2004.

Morelli, Federica, Territorio o nación. Reforma y disolución del espacio imperial en Ecuador, 1765-1830, Madrid, Centro de Estudios Políticos y Constitucionales, 2005 .

Moriconi, Miriam, “Administración Borbónica de pueblo de indios en el Río de la Plata. Matrícula de pueblos de Santa Fe (1785)", Prohistoria, XV/18 (Rosario, 2012): 144-197.

Moriconi, Miriam, "Intersecciones Críticas. Doctrineros en pueblos de indios de Santa Fe después de la expulsión de la Compañía de Jesús (1767-1804)", Revista de Ciencias Sociales, segunda época, VI/26 (Quilmes, primavera de 2014): 29-48.

Nesis, Florencia, Los grupos mocoví en el siglo XVIII, Buenos Aires, 2005.

Pietchsmann, Horst, "Un testimonio del impacto del reformismo borbónico en Nueva España: la representación del intendente de Puebla de los Ángeles de 27 de junio de 1792", Jahrbuch für Geschichte Lateinamerikas, 31 (Köln, 1994): 1-38.

Pietchsmann, Horst, Las reformas borbónicas y el sistema de intendencias en Nueva España. Un estudio político administrativo, México, FCE, 1996.

Romano, Silvia, "Instituciones coloniales en contextos republicanos: los jueces de la campaña cordobesa en las primeras décadas postrevolucionarias", Fabián Herrero (comp.), Revolución. Política e ideas en el Río de la Plata durante la década de 1810, Rosario, Prohistoria Ediciones, 2010.

Rustán, Elisabeth, De 'perjudiciales' a pobladores de la frontera. Poblamiento de la frontera sur de la Gobernación Intendencia de Córdoba a fines del siglo XVIII, Córdoba, Ferreyra Editor, 2005.

San Martino de Dromi, Laura, Intendencias y provincias en la historia argentina, Buenos Aires, CCA, 1992.

Serulnikov, Sergio, Conflictos sociales e insurrección en el mundo colonial andino. El norte de Potosi en el siglo XVIII, Buenos Aires, FCE, 2006.

Storni, Carlos Mario, Investigaciones sobre la historia del derecho rural argentino: españoles, criollos, indios y gauderios en la llanura pampeana, Buenos Aires, INHID, 1997.

Suárez, Teresa y Tornay, María Laura, "Poblaciones, vecinos y fronteras rioplatenses. Santa Fe a fines del siglo XVIII", Anuario de Estudios Americanos, LX/2 (Sevilla, julio-diciembre de 2003): 521-555. 
Tarragó, Griselda, "De las montañas al Río de la Plata: gobernadores cántabros en Buenos Aires (primera mitad del siglo XVIII)", Monte Buciero, 12 (Santoña, 2006).

Tarragó, Griselda, "The long kiss of goodbye: Santa Fe and the conflict over the privilege of puerto preciso (1726-1743)", Giuseppe De Luca y Gaetano Sabatini (eds.), Growing in the Shadow of an Empire. How Spanish Colonialism Affected Economic Development in Europe and in the World (XVIth-XVIIIth cc.), Milano, Franco Angeli Editore, 2012.

Tau Anzoátegui, Víctor y Martiré, Eduardo, Manual de historia de las instituciones argentinas, séptima edición actualizada, Buenos Aires, Librería Histórica, 2005.

Tío Vallejo, Gabriela, "Presencias y ausencias del Cabildo en la construcción del orden provincial: el caso de Tucumán, 1770-1830", Araucaria, IX/18 (Sevilla, 2007).

Tornay, María Laura, "La justicia rural en Santa Fe colonial. Cambios institucionales y sociales en el período borbónico", Actas del IV Encuentro de Historiadores de la Junta Provincial de Estudios Históricos de Santa Fe (2002), Santa Fe, 2004.

Tuella, Pedro, "Relación histórica del Pueblo y Jurisdicción del Rosario de los Arroyos en el Gobierno de Santa Fe, Provincia de Buenos Aires", Memorias y Noticias para servir á la historia antigua de la República Argentina. Compiladas y publicadas por los fundadores de la Revista de Buenos Aires, Buenos Aires, Imprenta de Mayo, 1865.

Viglione, Hebe, Historia de la población del Pago de los Arroyos: Padrón de 1738, familias, distribución espacial y actividades económicas, Buenos Aires, ANH, 2003.

Viglione, Hebe, "Población y poblamiento del área litoral fluvial argentina en el período colonial", Cesar A. García Belsunce (coord.), La población colonial, Buenos Aires, ANH, 2005.

Viglione, Hebe, "Familias sin hombres: mujeres jefas de hogar en el fin del virreinato del Río de la Plata. Pago de los Arroyos, Provincia de Santa Fe, Argentina", Temas Americanistas, 20 (Sevilla, diciembre-julio, 2008): 92-109.

Fecha de recepción: 27 de marzo de 2015.

Fecha de aceptación: 15 de junio de 2015. 


\section{Politics from the country: local initiatives and rural government in reformist times (Santa Fe, Vice Royalty of the Río de la Plata in the late eighteenth century)}

This article analyses the efforts made by a group of rural residents in Rio de la Plata to provide a missing chapter in the Royal Ordinance of Intendants of Buenos Aires (1782): the government of rural areas. The text posits that the dichotomic view "imposition or resistance" to the processes of centralisation does not do justice to the different historical experiences. Documenting the existence of a rich political life in an outlying rural area of the River Plate Viceroyalty during the last quarter of the eighteenth century, it illustrates the way in which territorial processes "from below" influenced the institutional architecture of the period.

KEY WORDS: politics; justice; bourbon reforms; rural government; Río de la Plata. 